\title{
Correspondence between performance of Eucalyptus spp trees selected from family and clonal tests
}

\author{
C.A.F. Reis ${ }^{1}$, F.M.A. Gonçalves ${ }^{1}$, L.N. Rosse $^{2}$, R.R.G.F. Costa $^{1}$ and \\ M.A.P. Ramalho ${ }^{1}$ \\ ${ }^{1}$ Departamento de Biologia, Universidade Federal de Lavras, Lavras, MG, Brasil \\ ${ }^{2}$ Empresa Veracel S.A., Eunápolis, BA, Brasil \\ Correspondence author: F.M.A. Gonçalves \\ E-mail: avelar@dbi.ufla.br
}

Genet. Mol. Res. 10 (2): 1172-1179 (2011)

Received September 24, 2010

Accepted December 7, 2010

Published June 21, 2011

DOI 10.4238/vol10-2gmr1078

\begin{abstract}
We examined the correspondence in performance between trees selected from a family test and their respective clones from a clonal test of Eucalyptus. Full-sib families were obtained from controlled pollination among individuals of Eucalyptus grandis and between E. grandis and E. urophylla. The hybridizations did not follow a factorial scheme. The family tests were carried out at three locations in Eunápolis and Itabela counties, in Bahia, Brazil, in 2003. Four hundred and ninety-seven high-performance trees were selected, by the individual BLUP procedure, in the family tests at two years of age, based on wood volume. The clones from these trees and 14 checks were evaluated in clonal tests carried out in the same region in 2006. The wood volume of the clones was evaluated at two years of age. Trait correlation between the trees selected from the family and clonal tests was low. The estimate of the coincidence between the best trees and the best clones using an average of the different intensities of selection was only $27 \%$. These results demonstrate that the selection of trees in the family test should not
\end{abstract}


be too drastic; otherwise the chance plus clones may be overlooked.

Key words: Forest breeding; Clonal selection; Genetic correlation; Individual BLUP procedure; Genotypes by years interaction

\section{INTRODUCTION}

One of the greatest genetic advances known in Brazil occurred in the breeding of the genus Eucalyptus. It was based on mass selection followed by the vegetative propagation of plus individuals. This procedure not only allowed a marked increase in wood yield but also yielded more homogeneous cultures, which made the production of cellulose and other products much more efficient and profitable in this country (Silva and Barrichelo, 2006).

The genetic progress with clonal selection was spectacular in the beginning, mainly because the companies had at their disposal millions of plants that originated from sexual propagation and evidently had applied a strong intensity of selection. During the two subsequent decades, some strategies aimed at improving the efficacy of the process, such as extensive evaluation of new clones, were adopted, since resampling of the population had not proven to promote additional gains (Gonçalves et al., 2001). Thus, clonal selection strategies were intensified. In this context, interspecific hybridization has become the fastest and most efficient strategy to obtain genetic gain, with direct and significant reflections on the industrial process (Assis and Mafia, 2007). Several authors, such as Bison et al. (2006) and Volker et al. (2008), have reported the results of interspecific hybridization. Plus individuals are chosen out of a family test to be used in clonal tests. Some articles in the literature have reported the performance of clones compared to their families obtained through open and controlled pollination, all evaluated in the same experiment. Gaspar et al. (2005) showed that there were no significant differences between the two types of plant material (cuttings versus seedlings) for the traits examined in the study. However, an important information that is not found in the breeding programs in Brazil is the correlation in performance between the plus tree and the clone derived from it. That is because they are evaluated in different environments, mainly years. Such information is essential to guide the strategies used by breeders to improve the success rate of selection.

The objective of this study was to determine the correlation between the trees selected from a family test and their respective clones in clonal tests.

\section{MATERIAL AND METHODS}

The experimental material was provided by the Veracel S.A. Forest Company and the experiments were conducted in two phases. The first phase involved a family test implemented at three locations, and the second phase consisted of clonal tests of trees selected from the family test.

\section{Family test}

The family test was evaluated at three Veracel S.A. locations in Eunápolis and Itabela, State of Bahia, Brazil, in 2003 (Table 1). The 45 full-sib families used were obtained from controlled pollination among individuals of Eucalyptus grandis and between individuals of $E$. grandis and E. urophylla. The hybridizations did not follow the factorial scheme. 


\begin{tabular}{|c|c|c|c|c|c|}
\hline Location & Latitude (S) & Longitude (W) & Precipitation $(\mathrm{mm})$ & Soil texture & Relief \\
\hline \multicolumn{6}{|c|}{ Family test } \\
\hline $\mathrm{A}$ & $16^{\circ} 20^{\prime} 50^{\prime \prime}$ & $39^{\circ} 35^{\prime} 57^{\prime \prime}$ & 1200 & Medium/clay & Flatland \\
\hline B & $16^{\circ} 16^{\prime} 19^{\prime \prime}$ & $39^{\circ} 45^{\prime} 45^{\prime \prime}$ & 1000 & Medium & Flatland/wavy \\
\hline $\mathrm{C}$ & $16^{\circ} 40^{\prime} 02^{\prime \prime}$ & $39^{\circ} 34^{\prime} 55^{\prime \prime}$ & 1300 & Medium & Flatland \\
\hline \multicolumn{6}{|c|}{ Clonal tests } \\
\hline $\mathrm{A}^{\prime}$ & $16^{\circ} 41^{\prime} 12^{\prime \prime}$ & $39^{\circ} 19^{\prime} 47^{\prime \prime}$ & 1300 & Sandy/medium/clay & Flatland \\
\hline $\mathrm{B}^{\prime}$ & $16^{\circ} 45^{\prime} 04^{\prime \prime}$ & $39^{\circ} 15^{\prime} 49^{\prime \prime}$ & 1300 & Sandy/clay & Flatland \\
\hline $\mathrm{C}^{\prime}$ & $16^{\circ} 45^{\prime} 04^{\prime \prime}$ & $39^{\circ} 15^{\prime} 49^{\prime \prime}$ & 1300 & Sandy/clay & Flatland \\
\hline
\end{tabular}

The experiments were carried out using a randomized complete block design with four replications, six plants per plot, and spacing of $3 \times 3 \mathrm{~m}$. Three commercial clones of the company were used as controls. The silvicultural management used was the same as that followed in the commercial stands.

In 2005, when the plants were two years old, the wood volume in cubic meters of all individuals from the three locations was estimated by the expression:

$$
\mathrm{V}=0.42 \frac{\pi \mathrm{DBH}^{2}}{40,000} \mathrm{H}
$$

where $V$ is the wood volume in cubic meters; $D B H$ is the breast height diameter in centimeters; $H$ is the height in meters, and 0.42 is the average shape factor of the tree, which converts the cylindrical volume into real volume.

The genetic evaluation of the family test was performed by using the mixed model methodology: REML/BLUP - restricted maximum likelihood/best linear unbiased prediction (Patterson and Thompson, 1971; Henderson, 1975). For this purpose, the SELEGEN software, a computer program for genetic selection in the breeding of perennial species (Resende, 2007), was used. The analyses were performed according to the following statistical model: $y=X r$ $+Z g+W p+e$, where $y$ is a vector of data, $r$ is a vector of fixed effects of repetition added to the general average; $g$ is a vector of random effects of individual genotypic $g \sim \mathrm{N}\left(0, \sigma_{\mathrm{g}}^{2}\right) ; p$ is a vector of random effects of plot $p \sim \mathrm{N}\left(0, \sigma_{\mathrm{p}}^{2}\right)$, and $e$ is a vector of random effects of errors or residues. The capital letters represent the matrix of incidence for the referred effects.

In the joint analysis the statistical pattern was: $y=X r^{\prime}+Z g+W p+T i+e$, in which $r^{\prime}$ is a vector of fixed effects of combination repetition-local added to the general average, and $i$ is a vector of random effects of genotypes by interaction of locations. The letter $\mathrm{T}$ represents the matrix of incidence for the referred effect. The other components are identical to the previous model.

Through these analyses, the components of variance for site by site and across sites were estimated and the genotypic values of the individuals were predicted. Using the individual BLUP procedure, 497 best performing trees in the family test were selected, where 105 trees were selected at location A of the family test, 204 trees at location B, and 188 trees at location C.

\section{Clonal tests}

The three clonal tests were carried out in the same counties as the family test, in 2006 
(Table 1). A randomized complete block design was used, with 20 replications, single tree plot, each plant occupying an area of $7.5 \mathrm{~m}^{2}$. Fourteen commercial clones from the company were used as controls. The silvicultural management used was identical to that used in commercial stands.

The wood volume, in cubic meters, was evaluated at the age of two years in the clonal tests. The evaluations were also performed using the SELEGEN computational program (Resende, 2007). The analyses were carried out considering the following statistical model: $y=X r$ $+Z g+e$, where $y$ is a vector of data; $r$ is a vector of fixed data of repetition added to general average; $g$ is a vector of random genotypic effects, and $e$ is a vector of random effects of errors or residues. The capital letters represent the matrix of incidence for the referred effects.

\section{Correspondence between performance of selected trees from family and clonal tests}

The correspondence between performance of selected trees from family and clonal tests was evaluated by two strategies:

a) Estimate of the genetic correlation between performance of selected trees from the family test and their respective clones in the clonal tests, according to an estimator presented by Bernardo (2002):

$$
r_{g_{t c}}=\frac{C O V g_{t c}}{\sqrt{\sigma_{g_{t}}^{2} \sigma_{g_{c}}^{2}}}
$$

where $C O V_{g_{t c}}$ is the genetic covariance between performances of selected trees from the family test and their respective clones; $\sigma^{2} g_{t}$ is the genetic variance obtained from REML/BLUP of trees selected in the family test, and $\sigma^{2} g_{c}$ is the genetic variance obtained from REML/BLUP of the clones in the clonal test, without checks.

Estimate of the genetic correlation between performance of selected trees from the family test and their respective clones in the clonal tests, according to an estimator presented by Notter and Diaz (1993):

$$
r_{g_{N D}}=\frac{r_{g_{t c}}}{a_{t} \cdot a_{c}}
$$

where $r_{g_{t c}}$ is the genetic correlation between performance of selected trees from the family test and their respective clones in the clonal tests, according to an estimator presented by Bernardo (2002); $a_{t}$ is the accuracy of trees selected from the family test obtained from REML/BLUP, and $a_{c}$ is the accuracy of the clones in the clonal test obtained from REML/BLUP, without checks.

b) Estimates of the coincidence index, that is, the proportion of superior and inferior trees in the family test with the same behavior in the clonal test, disregarding the chance of effect. The selection intensities of 5, 10, 15, 20, and 25\% were considered for the analyses. For this purpose, the Hamblin and Zimmermann (1986) expression was used: 


$$
C I=\frac{X-Y}{Z-Y} * 100
$$

where $X$ is the number of selected trees or clones, common to both environments; $Y$ is the number of randomly selected trees or clones in both environments, estimates considering selection intensity of the value $X$ (Hamblin and Zimmermann, 1986), and $Z$ is the number of selected trees and clones in one of the environments.

\section{RESULTS}

The average performance of the families, in volume, varied between the field trials. Location $\mathrm{C}$ showed the best performance, with $63.60 \%$ higher average volume than in location $\mathrm{B}$, which recorded the lowest growth (Table 2). Significant effect of the families in the site by site as well as in the multi-site analyses was observed (data not shown). The estimates of the selective accuracy were all higher than $86 \%$, indicating a good experimental precision in the evaluation of the experiments.

\begin{tabular}{|c|c|c|c|c|}
\hline \multirow[t]{2}{*}{ Parameter } & \multicolumn{3}{|c|}{ Locations } & \multirow[t]{2}{*}{ Joint analysis } \\
\hline & A & B & $\mathrm{C}$ & \\
\hline Genetic variance between full-sib families & 204.00 & 79.00 & 351.00 & 190.00 \\
\hline Phenotypic variance within the plot & $1,197.00$ & 496.00 & $1,383.00$ & $1,032.00$ \\
\hline Genetic variance within the plot & 833.00 & 339.00 & $1,113.00$ & 768.00 \\
\hline Environment variance within the plot & 364.00 & 157.00 & 270.00 & 264.00 \\
\hline Heritability of the family average & $\begin{array}{c}77.63 \\
(61.92-85.97)^{*}\end{array}$ & $\begin{array}{c}75.65 \\
(58.34-85.03)^{*}\end{array}$ & $\begin{array}{c}82.81 \\
(69.90-89.47)^{*}\end{array}$ & - \\
\hline Variance of the interaction between families and locations & - & - & - & 25.00 \\
\hline Accuracy $(\%)$ & 88.10 & 86.97 & 91.00 & 91.19 \\
\hline Average & 0.0743 & 0.0492 & 0.0805 & 0.0672 \\
\hline
\end{tabular}

*Confidence interval of heritability of the family average estimated according to Knapp et al. (1985).

The estimates of the variance components in the family test are presented in Table 2. It can be noticed that the highest estimate of genetic variance between families was obtained at location $\mathrm{C}$ and the lowest at location $\mathrm{B}$. The estimate of the variance component within families was superior to the genetic variance obtained between the families (Table 2). The estimate of variance for the interaction families $\mathrm{x}$ locations was of low magnitude, corresponding to only $14 \%$ of the genetic variance between families (Table 2 ). The estimates of genetic correlations between performances in families from several locations, two by two, had a higher magnitude. The genetic correlation between locations A and B was 1.00, between locations $\mathrm{A}$ and $\mathrm{C}, 0.97$, and between $\mathrm{B}$ and $\mathrm{C}, 0.83$. The estimated heritability for selection based on means of full-sib families varied from 75.65 to $82.81 \%$, and the estimates of the confidence intervals showed that they are different from zero, at $95 \%$ probability (Table 2 ).

In the clonal evaluation of the trees selected from the previous stage, it was observed that the average performance of the clones was similar in the experiments (Table 3). Significant effects of clones were observed (data not shown) according to the likelihood ratio test $(\mathrm{P} \leq 0.01)$. The estimates of mean of clonal heritability were greater than $74 \%$, all being different from zero, at $95 \%$ probability. These results are concordant with the high magnitudes of accuracy. 


\begin{tabular}{|c|c|c|c|}
\hline \multirow[t]{2}{*}{ Parameter } & \multicolumn{3}{|c|}{ Locations } \\
\hline & $\mathrm{A}^{\prime}$ & $\mathrm{B}^{\prime}$ & $C^{\prime}$ \\
\hline Genetic variance between clones & 429.00 & 395.00 & 390.00 \\
\hline Residual variance & 340.00 & 265.00 & 270.00 \\
\hline Heritability for the clonal selection & $\begin{array}{c}96.18 \\
(94.88-97.06)^{*}\end{array}$ & $\begin{array}{c}74.90 \\
(69.15-79.18)^{*}\end{array}$ & $\begin{array}{c}74.27 \\
(68.16-78.83)^{*}\end{array}$ \\
\hline Accuracy (\%) & 98.07 & 86.54 & 86.18 \\
\hline Average & 0.0711 & 0.0609 & 0.0626 \\
\hline
\end{tabular}

*Confidence interval of heritability for the clonal selection estimated according to Knapp et al. (1985).

The estimate of genetic correlation between the value of the tree in the family test and the average of the clone originating from it were low and varied from test to test (Table 4). In clonal test $\mathrm{A}$, where 105 clones were evaluated, the estimate of correlation was zero. The estimates of genetic correlation obtained from the expression of Notter and Diaz (1993) were higher, as expected, although still of low magnitude.

\section{Table 4. Estimates of genetic parameters for volume $\left(\mathrm{m}^{3} / \mathrm{plant} \times 10^{6}\right)$.}

\begin{tabular}{|c|c|c|c|}
\hline \multirow[t]{2}{*}{ Parameter } & \multicolumn{3}{|c|}{ Tests } \\
\hline & $\mathrm{A} / \mathrm{A}^{\prime}$ & $\mathrm{B} / \mathrm{B}^{\prime}$ & $\mathrm{C} / \mathrm{C}^{\prime}$ \\
\hline Genetic covariance between trees selected from the family test and their clones & 0.00 & 29.50 & 66.00 \\
\hline Genetic variance of trees selected in family test & 3.00 & 36.00 & 90.00 \\
\hline Genetic variance of the clones in the clonal test & 429.00 & 395.00 & 390.00 \\
\hline Accuracy of trees selected from the family test & 21.65 & 88.75 & 87.90 \\
\hline Accuracy of the clones in the clonal test & 98.05 & 86.55 & 86.20 \\
\hline Genetic correlation $^{1}$ & 0.0000 & 0.2475 & 0.3525 \\
\hline Genetic correlation $^{2}$ & 0.0000 & 0.3220 & 0.4650 \\
\hline
\end{tabular}

${ }^{1}$ Genetic correlation between performance of trees selected from the family test and their respective clones in the clonal tests according to an estimator presented by Bernardo (2002). ${ }^{2}$ Genetic correlation between performance of trees selected from the family test and their respective clones in the clonal tests according to an estimator presented by Notter and Diaz (1993).

Another procedure used to evaluate the efficiency of the selection of trees was estimating the coincidence index (Table 5). It was observed that all the indices were low, especially when the worst clones were considered to be in the selection, when 5,10 , or $15 \%$ of selection intensity was applied. The coincidence index increased with increase in number of selected clones.

Table 5. Estimates of coincidence index (CI) in the classification of the best or worst trees from family test and from clonal test, using different selection intensities.

\begin{tabular}{lrrrrrr}
\hline & \multicolumn{5}{c}{ Selection intensities } \\
\cline { 2 - 7 } & \multicolumn{1}{c}{$5 \%$} & $10 \%$ & $15 \%$ & $20 \%$ & $25 \%$ & Average \\
\hline Best & 22.70 & 23.80 & 22.20 & 31.80 & 34.30 & 27.00 \\
Worst & 0.00 & 9.50 & 14.30 & 17.70 & 29.50 & 14.20 \\
\hline
\end{tabular}

Data are reported as $\mathrm{CI}$ in percent. 


\section{DISCUSSION}

The average wood volume of the families varied between the locations (Table 2). Considering that the soil fertility did not differ between the locations, this difference probably occurred due to the differences in the average annual precipitation between them (Table 1).

The good association between the performance of the families at the different locations is a consequence of the elevated magnitude of the genetic correlation estimates between family performances in the various locations, and it proves to be the absence of the interaction between families and locations. The interaction Eucalyptus families x locations, in experiments conducted at experimental areas of the companies in Brazil, is not very expressive according to Mori et al. (1988), Santos et al. (1990), Pereira et al. (1997), and Nunes et al. (2002). In other countries, the contribution of the interaction families $\mathrm{x}$ locations seems to be more pronounced (MacDonald et al., 1997; Costa e Silva et al., 2006).

The estimated heritability for selection based on means of full-sib families was high (Table 2). The majority of the estimates of the available heritability in Brazil were mainly obtained with half-sib families that explore only $1 / 4$ additive variance $\left(1 / 4 \sigma^{2}\right)$. When full-sib families are used, as in this study, $1 / 2 \sigma^{2}{ }_{A}+1 / 4 \sigma^{2}$ is explored. At this point, it is necessary to emphasize that there are not many available estimates of the dominance variance $\left(\sigma_{D}^{2}\right)$ for volume in the genus Eucalyptus. There are reports that it could be expressive (Bouvet et al., 2009), and there are other findings that it is not expressive as in the case of E. globulus in Europe. In Brazil, reports of Bison et al. (2006) show that there is dominance for wood volume, but not of great magnitude. In spite of its low significance, it will contribute to the increase in heritability estimates. Nevertheless, it should be emphasized that these estimates are more useful in recurrent selection programs. In this research, all genetic variance is explored.

Considering the trials with clonal tests, the similarity in the average performance in volume (Table 3 ) can be related to the fact that they were located geographically very close to each other and hence had similar climate and soil fertility conditions, as well as similar latitude, that is, similar environmental conditions (Table 1). It was observed that variability among the clones occurred, which demonstrates the possibility of gains with the selection. The high heritability estimates in clones provide a very favorable condition for selection (Table 3).

What is of great interest in this research is the degree of association between the trees selected from the family test and from their respective clones. Genetic correlations between the performance of the tree in the family test and the clone derived from it were very low. Confirming these results, the coincidence index estimate between the best trees in the family test and their clones, in the average of different selection intensity, was only $27 \%$. As the accuracy in the experiments by local was high, the estimate of correlation by expressions from Bernardo (2002) and Notter and Diaz (1993) was similar (Table 4).

In a study carried out in Europe with E. globulus, Gaspar et al. (2005) noticed that the performance of clones and their family, evaluated in the same experiment, was similar. On the other hand, the simulation of Borralho and Kanowski (1994) showed that the correlation between seedlings and propagules taken from them is expected to be of low magnitude. Even though the situation of the present study is not exactly the same, it is possible to infer that the low estimate of the genetic association between the elite trees and clone performance should be attributed to the interaction of genotypes $\mathrm{x}$ years. By confirming the presence of a marked interaction between genotypes and years, the option would be to make a less drastic selection 
of the trees in the family test to increase the chance of identifying truly plus clones.

\section{ACKNOWLEDGMENTS}

Research supported by CAPES and FAPEMIG. The authors thank Veracel S.A. for the opportunity to conduct this study in the company.

\section{REFERENCES}

Assis TF and Mafia RG (2007). Hibridação e Clonagem. In: Biotecnologia Florestal (Borém A, ed.). Editora UFV, Viçosa, 93-121.

Bernardo R (2002). Breeding for Quantitative Traits in Plants. Stemma Press, Woodbury.

Bison O, Ramalho MAP, Rezende GDSP, Aguiar AM, et al. (2006). Comparison between open progenies and hybrids performance in Eucalyptus grandis and Eucalyptus urophylla. Silvae Genet. 55: 192-196.

Borralho NMG and Kanowski PJ (1994). Correspondence between performance of genetically related clones and seedlings. Can. J. For. Res. 25: 500-506.

Bouvet JM, Saya P and Vigneron P (2009). Trends in additive, dominance and environmental effects with age for growth traits in Eucalyptus hybrid populations. Euphytica 165: 35-54.

Costa e Silva J, Potts BM and Dutkowski GW (2006). Genotype by environment interaction for growth of Eucalyptus globulus in Australia. Tree Genet. Genomes 2: 61-75.

Gaspar MJ, Borralho N and Gomes AL (2005). Comparison between field performance of cuttings and seedlings of Eucalyptus globulus. Ann. For. Sci. 62: 837-841.

Gonçalves FMA, Rezende GDSP, Bertolucci F de LG and Ramalho MAP (2001). Progresso genético por meio da seleção de clones de eucalipto em plantios comerciais. Rev. Árvore 25.: 295-301.

Hamblin JE and Zimmermann MJ de O (1986). Breeding common bean for yield in mixtures. Plant Breed. Rev. 4: 245272.

Henderson CR (1975). Best linear unbiased estimation and prediction under a selection model. Biometrics 31: 423-447.

Knapp SJ, Stroup WW and Ross WM (1985). Exact confidence intervals for heritability on a progeny mean basis. Crop Sci. 25: 192-194.

MacDonald AC, Borralho NMG and Potts BM (1997). Genetic variation for growth and wood density in Eucalyptus globulus ssp. globulus in Tasmania (Australia). Silvae Genet. 46: 236-241.

Mori ES, Kageyama PY and Ferreira M (1988). Variação genética e interação progênies x locais em Eucalyptus urophylla. Rev. IPEF 39: 53-63.

Notter DR and Diaz C (1993). Use of covariances between predicted breeding values to assess the genetic correlation between performance in two environments. Genet. Sel. Evol. 25: 353-372.

Nunes GHS, Rezende GDSP, Ramalho MAP and Santos JB dos (2002). Implicações da interação genótipos x ambientes na seleção de clones de eucalipto. Rev. Cerne 8: 49-58.

Patterson HD and Thompson R (1971). Recovery of inter-block information when block sizes are unequal. Biometrika 58: 545-554.

Pereira AB, Marques Júnior OG, Ramalho MAP and Althoff P (1997). Eficiência da seleção precoce em famílias de meiosirmãos de Eucalyptus camaldulensis Dehnh., na região noroeste do Estado de Minas Gerais. Rev. Cerne 3: 33-40.

Resende MDV (2007). Software Selegen - REML/ BLUP: Sistema Estatístico e Seleção Genética Computadorizada Via Modelos Mistos. Embrapa Florestas, Colombo.

Santos PET, Garcia CH, Mori ES and Moraes MLT (1990). Potencial para programas de melhoramento, estimativas de parâmetros genéticos e interação progênies x locais em populações de Eucalyptus urophylla. Rev. IPEF 43/44: 11-19.

Silva PHM and Barrichelo LEG (2006). Progressos Recentes na Área Florestal. In: Ciência, Agricultura e Sociedade (Paterniani E, ed.). Embrapa Informação Tecnológica, Brasília, 439-456.

Volker PW, Potts BM and Borralho NMG (2008). Genetic parameters of intra and inter-specific hybrids of Eucalyptus globulus and Eucalyptus nitens. Tree Genet. Genomes 4: 445-460. 